\title{
Evaluation of preoperative corneal astigmatism using swept- source optical biometry in Chinese cataract surgery candidates with high myopia: a prospective, comparative observational study
}

\author{
Yehui Tan, Liangping Liu, Jianbing Li, Yingyan Qin, Ao Sun, Mingxing Wu \\ State Key Laboratory of Ophthalmology, Zhongshan Ophthalmic Center, Sun Yat-sen University, Guangzhou, China \\ Contributions: (I) Conception and design: Y Tan, M Wu; (II) Administrative support: M Wu; (III) Provision of study materials or patients: L Liu, Y \\ Qin, A Sun, M Wu; (IV) Collection and assembly of data: Y Tan, L Liu, J Li, Y Qin, A Sun; (V) Data analysis and interpretation: Y Tan, L Liu, J Li, \\ $\mathrm{M} \mathrm{Wu}$; (VI) Manuscript writing: All authors; (VII) Final approval of manuscript: All authors. \\ Correspondence to: Prof. Mingxing Wu, MD, PhD. State Key Laboratory of Ophthalmology, Zhongshan Ophthalmic Center, Sun Yat-sen University, \\ No. 7, Jinsui Road, Zhujiang Newtown, Guangzhou 510060, China. Email: wumingx@mail.sysu.edu.cn.
}

Background: High myopia and cataracts are major causes of blindness in East and Southeast Asia. Corneal
astigmatism is a major contributor to uncorrected poor vision after cataract surgery in patients with high
myopia. The purpose of the present study was to evaluate the demographic characteristics and distribution of
preoperative corneal astigmatism in Chinese cataract surgery candidates with high myopia.
Methods: Swept-source optical coherence tomography-based optical biometry was performed
preoperatively in consecutive cataract surgery candidates who were classified by axial length (AL) into a high
myopia group (defined as $\mathrm{AL} \geq 26.0 \mathrm{~mm})$ and a control group (normal ALs). The demographics, ALs, and
keratometry values were recorded.
Results: Among 15,063 cataract surgery candidates $(15,063$ eyes), 1,921 patients (12.8\%, 1,921 eyes) in the
high myopia group and 11,880 patients $(11,880$ eyes) in the control group were enrolled. In the high myopia
group, the mean age was $59.8 \pm 12.6$ (standard deviation) years, which was younger than that in the control
group (69.1 \pm 11.0 years, $\mathrm{P}<0.001)$. In the high myopia group, the mean corneal astigmatism was $1.20 \pm 0.83$
dioptre (D), which was greater than that in the control group $(0.93 \pm 0.69 \mathrm{D}, \mathrm{P}<0.001)$. In the high myopia
group, $82.2 \%$ had corneal astigmatism $\geq 0.50 \mathrm{D}, 51.4 \% \geq 1.00 \mathrm{D}, 27.4 \% \geq 1.50 \mathrm{D}$ and $14.4 \% \geq 2.00 \mathrm{D}$, all of
which were higher than the respective proportions in the control group $(\mathrm{P}<0.001$ for all). In the high myopia
group, $66.8 \%$ had moderate to high corneal astigmatism, and $42.8 \%$ had "with-the-rule" astigmatism, and
both of these proportions were higher than the respective proportions in the control group (P<0.001 for
both). In the high myopia group, corneal astigmatism tended to increase with increasing age $(\mathrm{r}=0.134$,
$\mathrm{P}<0.001)$ after the age of 50 , which was consistent with the tendency in the control group.

Conclusions: A significant burden of preoperative corneal astigmatism was observed in Chinese cataract surgery candidates with high myopia. Moderate to high corneal astigmatism was more common in highly myopic eyes than in normal AL eyes.

Keywords: Corneal astigmatism; high myopia; cataract; cataract surgery; swept-source optical coherence tomography

Submitted Oct 06, 2020. Accepted for publication Feb 04, 2021.

doi: 10.21037/atm-20-6757

View this article at: http://dx.doi.org/10.21037/atm-20-6757 


\section{Introduction}

High myopia, which is characterized by axial elongation and typically defined as an axial length (AL) $\geq 26.0 \mathrm{~mm}(1,2)$, is a common risk factor for cataracts; for each millimeter increase in AL, there is a 3.8-fold increase in the likelihood of developing nuclear cataracts (3) and a 1.29-fold increase in the likelihood of developing posterior subcapsular cataracts (PSCs) (4). High myopia and cataracts are major causes of blindness in East and Southeast Asia, especially in China $(5,6)$. The prevalence of high myopia in cataract patients has shown an upward trend accompanied by a significant increase in the number of high myopia patients globally (7). Due to advances in phacoemulsification techniques, intraocular lens (IOL) power calculations and IOL design, cataract surgery is routinely performed in patients with high myopia $(6,8)$. In particular, those who suffer from both cataracts and corneal astigmatism can now undergo implantation of a toric IOL, which corrects corneal astigmatism to improve postoperative visual acuity and increase spectacle independence (9-11). Findings in several studies (11-14) have suggested that corneal astigmatism is a major contributor to uncorrected poor vision after cataract surgery and that correcting residual astigmatism can greatly improve visual acuity both at a distance and up close.

The distribution of preoperative corneal astigmatism in patients with age-related cataracts (ARCs) who are undergoing routine cataract surgery has been reported by teams from China, Thailand, and the United Kingdom (UK), and the proportions of eyes with corneal astigmatism $\geq 1.00$ dioptre (D) were $41.3 \%$ (15), 37.8\% (16), and $42 \%$ (17), respectively. A recent study conducted by Jing et al. (18) found that posterior corneal astigmatism decreased with age and remained as "against-the-rule" (ATR) astigmatism in most cataract patients with high myopia; there was no significant difference in posterior corneal astigmatism between patients with high myopia and those without high myopia. In myopia patients without cataracts, two previous studies $(19,20)$ on total astigmatism (including corneal astigmatism and internal astigmatism) found that there was a negative correlation between myopic severity and cylinder power; younger age $(<16$ years) was associated with higher cylinder power, but the clinical significant astigmatism $(\geq 1.00 \mathrm{D})$ was not associated with myopia progression. However, to the best of our knowledge, few reports have systematically evaluated anterior corneal astigmatism (referred to as "corneal astigmatism" in previous studies) (15-17) in cataract patients with high myopia, and until now, the prevalence and distribution of corneal astigmatism in patients with high myopia before cataract surgery have remained unclear. Therefore, we analysed the distribution of preoperative corneal astigmatism in cataract surgery candidates with high myopia and compared it with that in individuals with normal ALs.

A newly available swept-source optical coherence tomography (SS-OCT)-based optical biometry device, named the IOLMaster 700 (Carl Zeiss Meditec AG, Jena, Germany), enables OCT imaging and visualization across the entire length of the eye. For keratometry and astigmatism measurements, the IOLMaster 700 has shown excellent repeatability and has been shown to agree with Scheimpflug-based topography (Pentacam; Oculus, Wetzlar, Germany) (21-23). Moreover, the IOLMaster 700 has been shown to be more effective than the IOLMaster 500 (Carl Zeiss Meditec AG, Jena, Germany) in measuring AL in eyes with nuclear cataracts and PSCs (24), and it is easier to perform $\mathrm{AL}$ measurements in longer eyes ( $\mathrm{AL} \geq 30.0 \mathrm{~mm}$ ) with the IOLMaster 700 than with the Lenstar 900 (HaagStreit AG, Koeniz, Switzerland) (25).

In this study, we prospectively collected AL and keratometry data measured by the IOLMaster 700 and demographic data before cataract surgery to evaluate the demographic characteristics and distribution of preoperative corneal astigmatism in Chinese cataract surgery candidates with high myopia. We present the following article in accordance with the STROBE reporting checklist (available at http://dx.doi.org/10.21037/atm-20-6757).

\section{Methods}

\section{Study design}

In this prospective study, Chinese patients aged 18 years or older scheduled to undergo cataract surgery between August 2018 and January 2020 at the Zhongshan Ophthalmic Center, Sun Yat-sen University (Guangzhou, China), were consecutively enrolled. Patients were classified into two groups according to AL: the high myopia group included cataract patients with high myopia (defined as AL $\geq 26.0 \mathrm{~mm}$ ) $(1,2)$, and the control group included cataract patients with normal ALs $(22.0 \leq \mathrm{AL} \leq 25.0 \mathrm{~mm})(6,26)$. Patients with a history of ocular surgeries or ocular trauma, corneal or ocular surface diseases, uveitis, glaucoma, or wearing contact lenses within the previous two weeks were excluded. Ethics approval was obtained from the Human Ethics 
Committee of the Zhongshan Ophthalmic Center (No. 2019KYPJ124), and informed consent was obtained from all participants. All procedures in the study were performed in adherence with the tenets of the Declaration of Helsinki (as revised in 2013).

\section{Ophthalmic examinations and definitions}

After collecting relevant past medical history data, all cataract patients had a standard ophthalmological examination including visual acuity, intraocular pressure, slit-lamp biomicroscopy and a fundus examination through dilated pupils. Biometric parameters in both eyes of each patient were measured preoperatively using a new SS-OCTbased biometry tool (IOLMaster 700, version 1.50, Carl Zeiss Meditec AG, Jena, Germany). The keratometric values provided by the IOLMaster 700 in the central $2.5 \mathrm{~mm}$ zone were measured in two meridians: flat keratometry (K1) and steep keratometry (K2). Corneal astigmatism was calculated as the absolute difference between $\mathrm{K} 2$ and $\mathrm{K} 1$ and was divided into three subgroups according to astigmatism severity as follows: low $(<0.75 \mathrm{D})$, moderate $(0.75-2.50 \mathrm{D})$ and high corneal astigmatism $(>2.50 \mathrm{D})$ $(14,27)$. We classified corneal astigmatism by axis as "withthe-rule" (WTR) when the axis of the correcting minus cylinder was within $180 \pm 30$ degrees (the steep corneal meridian being within $90 \pm 30$ degrees in this case), as ATR when the correcting minus cylinder axis was within $90 \pm 30$ degrees, and as oblique when it was other degree values $(17,28)$. Additionally, we divided the highly myopic eyes into three subgroups according to AL (indicating myopic severity) as follows: mild $(26.0 \leq \mathrm{AL}<28.0 \mathrm{~mm})$, moderate $(28.0 \leq \mathrm{AL}<30.0 \mathrm{~mm})$ and extremely high myopia $(\geq 30.0 \mathrm{~mm})(1)$.

The biometric parameters of all patients were measured routinely by two experienced technicians. Three measurements or more were performed for each parameter, and the values were averaged. The demographic, $\mathrm{AL}$, keratometry (K1 and $\mathrm{K} 2$ ), and corneal astigmatism (including the cylinder and axis of astigmatism) data were recorded for analysis.

\section{Statistical analysis}

Data analyses were performed using Excel 2010 (Microsoft Corp., Redmond, WA, USA) and SPSS 23.0 (IBM Corp., Armonk, NY, USA). For patients with both eyes eligible, the right eye was used for analysis. The absolute frequency (n) and relative frequency (\%) were computed for qualitative variables, and the mean \pm standard deviation (SD) was computed for quantitative variables. The normality of the variable distributions was checked with the Kolmogorov-Smirnov test. Differences between groups were compared using an unpaired $t$ test or one-way analysis of variance (ANOVA) for normally distributed variables and a Wilcoxon or Kruskal-Wallis test for nonnormally distributed variables. Trend analysis was performed to detect statistically significant trend changes with age and myopic severity. The $\chi^{2}$ test was used to determine differences in categorical variables between groups. Possible correlations between variables were assessed using the Pearson or Spearman correlation coefficients depending on the parameter distributions. Propensity score matching (PSM) was used to remove the interference of confounding factors. All $\mathrm{P}$ values were two-sided, and a $\mathrm{P}$ value $<0.05$ was considered statistically significant.

\section{Results}

\section{Demographic characteristics of the study participants}

In all, among 15,063 cataract surgery candidates $(15,063$ eyes), 1,921 patients (12.8\%, 1,921 eyes) with high myopia (high myopia group) and 11,880 patients (11,880 eyes) with normal ALs (control group) were included in this analysis. Table 1 shows the demographic characteristics of the study participants. The AL distribution for the highly myopic eyes, which indicates the distribution of myopic severity, is shown in Figure 1. There were 621 eyes (32.3\%) with extremely high myopia (AL $\geq 30.0 \mathrm{~mm}$ ).

Figure 2 shows the distribution of patients in the high myopia and control groups according to age group. In the high myopia group, 900 patients (46.9\%) were younger than 60 years, which was significantly higher than the proportion in the control group $(15.7 \% ; \mathrm{P}<0.001)$.

\section{Distribution of corneal astigmatism in the high myopia and control groups}

Double-angle plots were used to visualize the astigmatism (cylinder and axis) distribution in the high myopia and control groups, as shown in Figure $3 A$. The bar graph shows the frequencies (\%) of astigmatism cylinders in $0.50 \mathrm{D}$ steps in the two groups (Figure 3B).

In the high myopia group, 1580 eyes $(82.2 \%)$ had corneal astigmatism $\geq 0.50 \mathrm{D}, 987$ eyes $(51.4 \%)$ had 
Table 1 Demographics of the study participants

\begin{tabular}{|c|c|c|c|}
\hline Parameter & High myopia group & Control group & $P$ value \\
\hline \multicolumn{4}{|l|}{ Age (years) } \\
\hline Mean \pm SD & $59.8 \pm 12.6$ & $69.1 \pm 11.0$ & \multirow[t]{2}{*}{$<0.001$} \\
\hline Median (range) & 61 (20 to 95$)$ & 70 (18 to 99$)$ & \\
\hline Male & $902(47.0)$ & $4,935(41.5)$ & \multirow[t]{2}{*}{$<0.001$} \\
\hline Female & $1,019(53.0)$ & $6,945(58.5)$ & \\
\hline \multicolumn{4}{|c|}{ Corneal astigmatism (D) } \\
\hline Mean \pm SD & $1.20 \pm 0.83$ & $0.93 \pm 0.69$ & $<0.001$ \\
\hline Mean \pm SD & $43.18 \pm 1.61$ & $43.72 \pm 1.44$ & \multirow[t]{2}{*}{$<0.001$} \\
\hline Median (range) & 43.15 (35.08 to 48.82 ) & 43.73 (35.90 to 49.41 ) & \\
\hline \multicolumn{4}{|l|}{$\mathrm{K} 2$ (D) } \\
\hline Mean \pm SD & $44.38 \pm 1.76$ & $44.66 \pm 1.47$ & \multirow[t]{2}{*}{$<0.001$} \\
\hline Median (range) & 44.32 (35.43 to 52.78$)$ & 44.62 (39.99 to 54.65 ) & \\
\hline \multicolumn{4}{|l|}{ Axial length (mm) } \\
\hline Mean \pm SD & $29.09 \pm 2.53$ & $23.46 \pm 0.72$ & \multirow[t]{2}{*}{$<0.001$} \\
\hline Median (range) & 28.48 (26.00 to 37.34$)$ & 23.45 (22.00 to 25.00$)$ & \\
\hline
\end{tabular}

SD, standard deviation; D, dioptres; K1, flat keratometry; K2, steep keratometry.

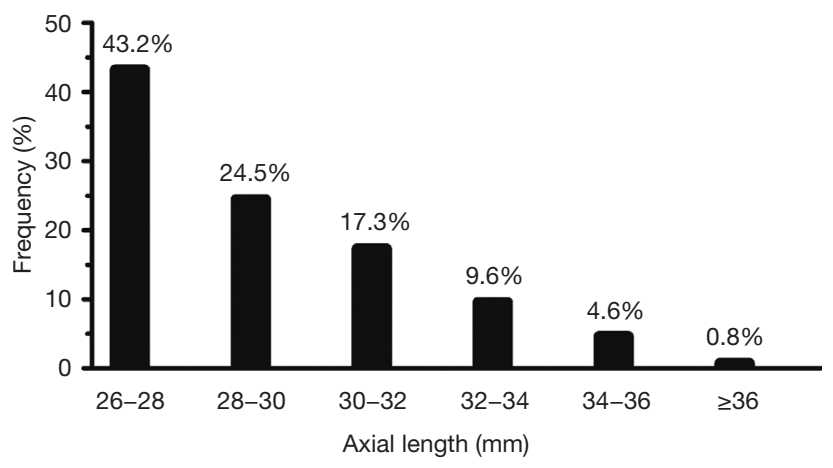

Figure 1 Axial length frequency (\%) in $2.00 \mathrm{~mm}$ steps in highly myopic eyes $(\mathrm{N}=1,921)$ indicating the distribution of myopic severity.

corneal astigmatism $\geq 1.00 \mathrm{D}$, and 526 eyes $(27.4 \%)$ had corneal astigmatism $\geq 1.50 \mathrm{D}$, and all of these proportions were significantly higher than the respective proportions observed in the control group (72.1\%, 36.0\% and $16.3 \%$, respectively; $\mathrm{P}<0.001$ for all), as shown in Figure $4 A$. In the high myopia group, 1,150 eyes $(59.9 \%)$ had moderate corneal astigmatism, and 133 eyes (6.9\%) had high corneal astigmatism, and both proportions were higher than the respective proportions in the control group $(\mathrm{P}<0.001$ for both) (Figure 4B). The mean corneal astigmatism in the high myopia group was greater than that in the control group in each of the 5 age subgroups after the age of 40 $(\mathrm{P}<0.001$ for all), as shown in Figure $4 C$. A significantly higher proportion of WTR astigmatism was found in the high myopia group (822 eyes, $42.8 \%$ ) than in the control group (28.1\%; $\mathrm{P}<0.001)$, as shown in Figure $4 D$.

Corneal astigmatism was not statistically correlated with $\mathrm{AL}$ in either the high myopia group $(\mathrm{r}=0.044, \mathrm{P}=0.054)$ or the control group $(\mathrm{r}=0.015, \mathrm{P}=0.102)$. In the high myopia group, corneal astigmatism was negatively correlated with age before the age of $50(\mathrm{r}=-0.129, \mathrm{P}=0.006)$; however, 


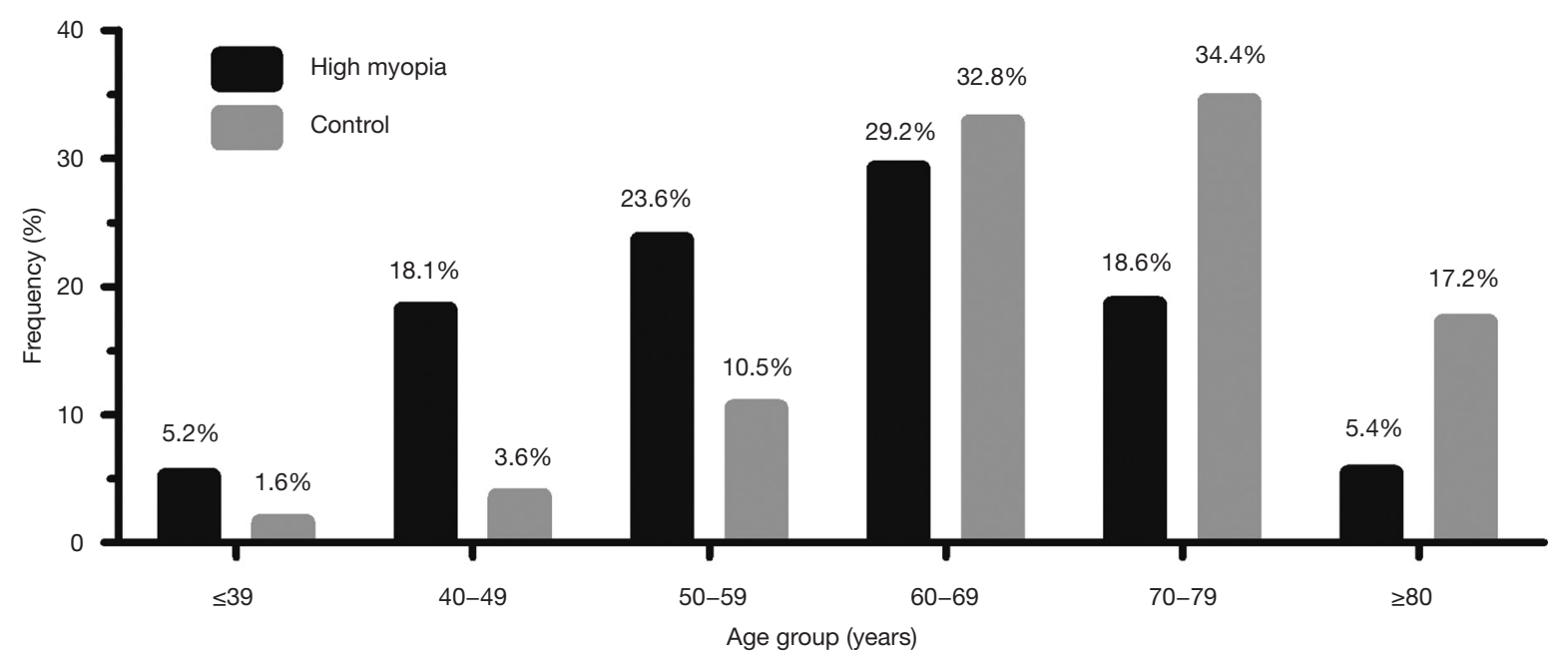

Figure 2 Frequency distributions of the samples in the high myopia and control groups according to age group. High myopia: the high myopia group, defined as $\mathrm{AL} \geq 26.0 \mathrm{~mm}, \mathrm{~N}=1,921$; control: the control group, $\mathrm{N}=11,880$.

after the age of 50, corneal astigmatism was positively correlated with age $(\mathrm{r}=0.134, \mathrm{P}<0.001)$, consistent with the correlation between corneal astigmatism and age in the control group $(r=-0.299$, and $r=0.286$, respectively; $\mathrm{P}<0.001$ for both).

Table 2 shows the astigmatism cylinder distributions according to astigmatism type in the two groups. The mean astigmatism cylinder in the high myopia group was significantly greater than that in the control group in each of the three astigmatism type subgroups $(\mathrm{P}<0.001$ for all). In the two groups, eyes with oblique astigmatism had a smaller mean astigmatism cylinder than eyes with WTR or ATR astigmatism.

\section{Corneal astigmatism distribution in high myopia patients by sex, age and myopic severity}

The distribution of corneal astigmatism in the patients with high myopia according to sex, age and myopic severity is summarized in Table 3. Among the high myopia patients, the mean corneal astigmatism and mean $\mathrm{AL}$ were statistically greater in women than in men $(\mathrm{P}<0.05$ for both). However, in the normal AL patients, men had greater mean corneal astigmatism and mean AL than women $(0.95$ $\mathrm{D}$ versus $0.92 \mathrm{D}$ and 23.72 versus $23.28 \mathrm{~mm}$, respectively; $\mathrm{P}<0.05$ for both). The proportion of WTR astigmatism decreased significantly with age, and the proportion of ATR astigmatism increased significantly with age $(\mathrm{P}<0.001$ for both). The proportion of oblique astigmatism was higher in women than in men $(\mathrm{P}=0.012)$, and the proportion of oblique astigmatism increased with myopic severity $(\mathrm{P}=0.026)$.

\section{Characteristics of corneal astigmatism in the two groups by astigmatism type}

The distributions of astigmatism cylinder levels across the three astigmatism types are shown in Figure $5 A$ (the high myopia group) and Figure $5 B$ (the control group). In the two groups, there were lower proportions of eyes with corneal astigmatism $\geq 0.50 \mathrm{D}, \geq 1.00 \mathrm{D}, \geq 1.50 \mathrm{D}$ and $\geq 2.00 \mathrm{D}$ in the eyes with oblique astigmatism than in the eyes with WTR or ATR astigmatism. Moreover, corneal astigmatism shifted with age from WTR to ATR astigmatism in both the high myopia group (Figure $5 C$ ) and the control group (Figure 5D).

\section{Distribution of corneal astigmatism in the two groups after adjustment for age and sex by PSM}

PSM was applied to adjust for the confounding factors of age and sex in the two groups, as shown in Table 4. After matching, the mean corneal astigmatism in the high myopia group was also greater than that in the control group $(1.20 \mathrm{D}$ versus $0.88 \mathrm{D}, \mathrm{P}<0.001)$, and $66.8 \%$ of the highly myopic eyes had moderate to high corneal astigmatism, which was significantly higher than the proportion in the control group $(48.2 \% ; \mathrm{P}<0.001)$. 
A

High myopia

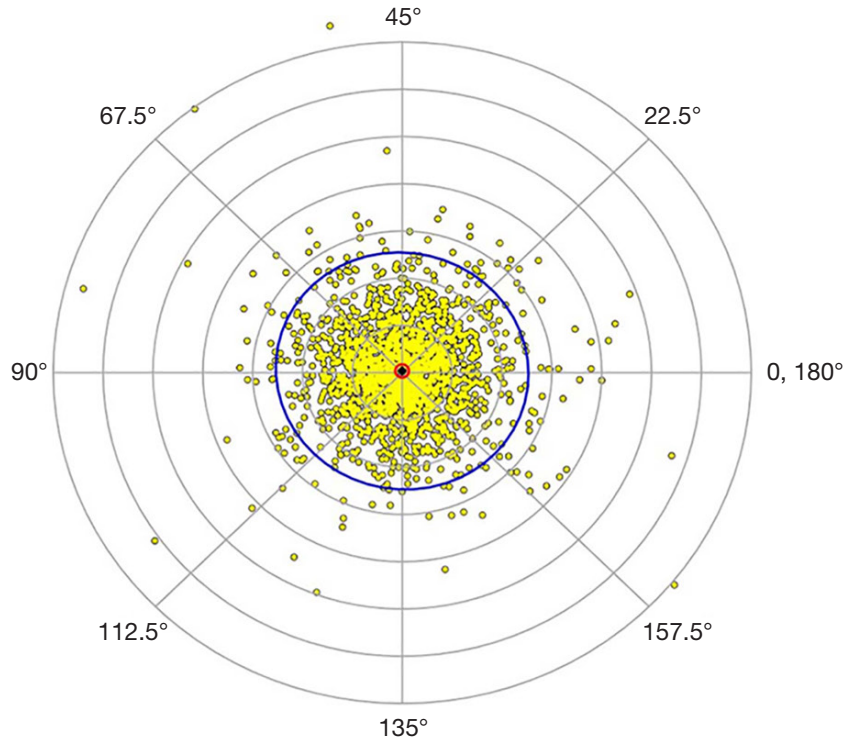

Centroid: 0.04 D @ 47․1.46 D; N=1,921
Control

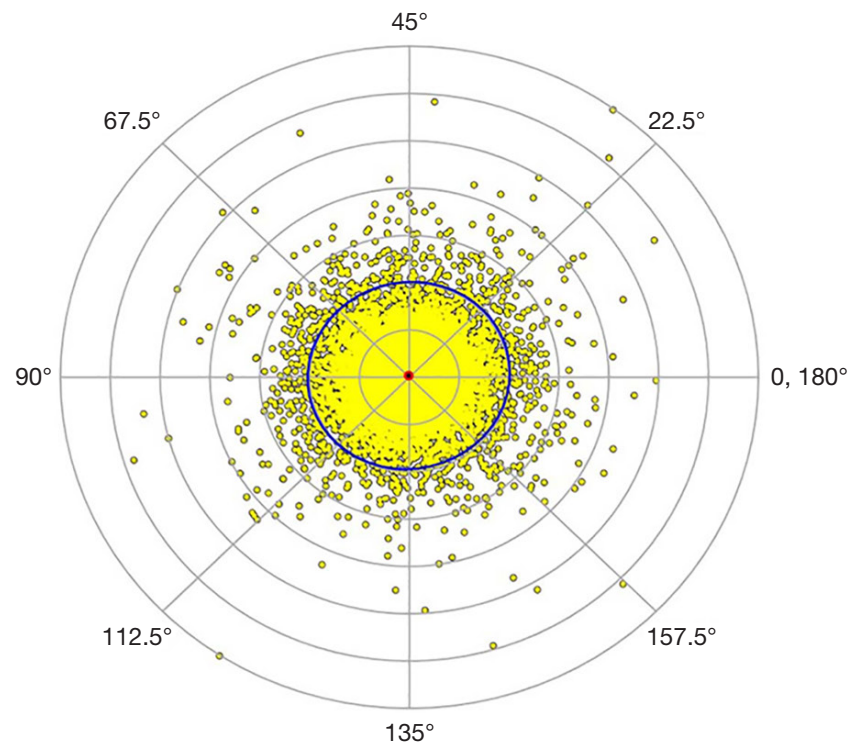

Centroid: 0.04 D @ 55土1.16 D; N=11,880

( $95 \%$ confidence ellipses of dataset $\bigcirc 95 \%$ confidence ellipses of centroid $\diamond$ Centroid $\bigcirc$ Each ring $=1.00 \mathrm{D}$

B

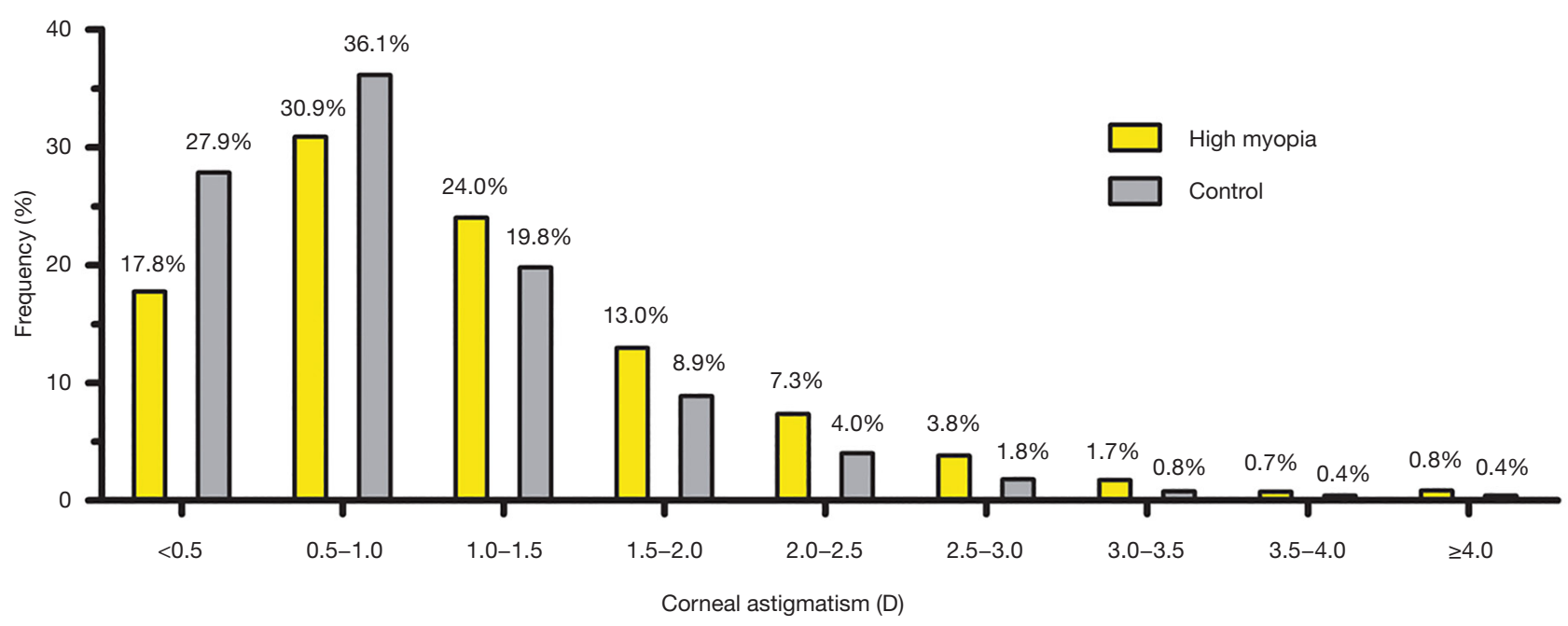

Figure 3 Distribution of corneal astigmatism in the high myopia and control groups. (A) Double-angle plots visualizing the astigmatism (cylinder and axis) distributions in the high myopia group $(\mathrm{N}=1,921)$ and in the control group $(\mathrm{N}=11,880)$. (B) Bar graph showing the frequencies (\%) of astigmatism cylinders in $0.50 \mathrm{D}$ steps in the two groups. 
A

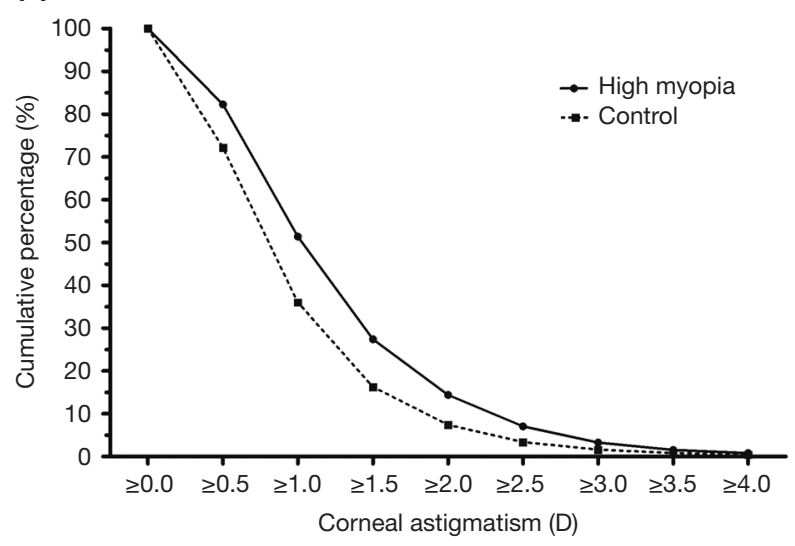

C

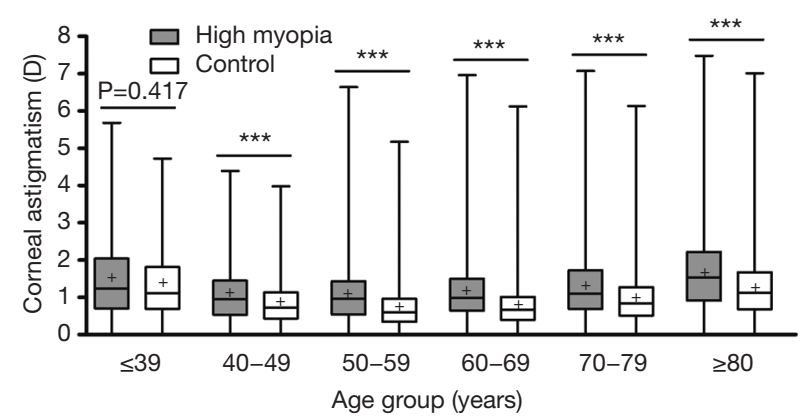

B

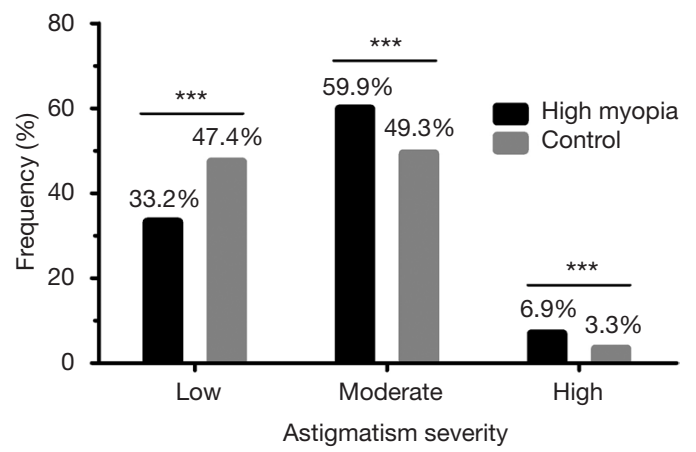

D

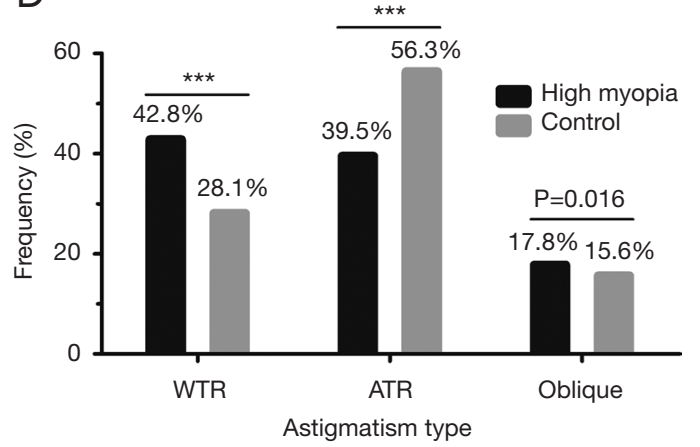

Figure 4 Differences in corneal astigmatism between the high myopia group and the control group. (A) Line chart comparing the cumulative percentages of eyes in $0.50 \mathrm{D}$ steps in the high myopia group $(\mathrm{N}=1,921)$ and the control group $(\mathrm{N}=11,880)$. (B) Comparisons of three categories according to astigmatism severity in the two groups. (C) The astigmatism cylinder values in the two groups according to age group. (D) The proportions of WTR, ATR and oblique astigmatism in the two groups. D, dioptres; WTR, with-the-rule; ATR, against-therule; ${ }^{* * *} \mathrm{P}<0.001$.

Table 2 Corneal astigmatism cylinder (D) for the high myopia and control groups according to astigmatism type

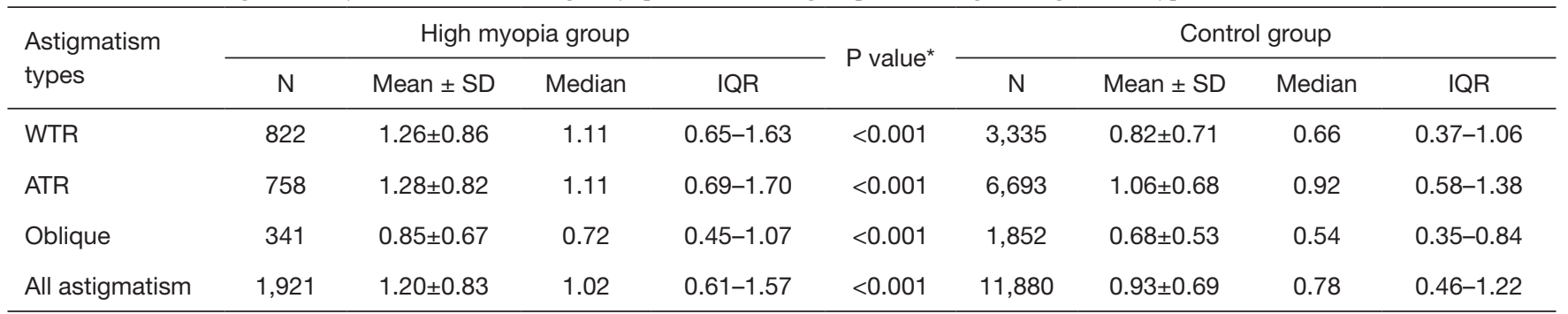

*High myopia group versus control group on the mean astigmatism cylinder. D, dioptres; SD, standard deviation; IQR, interquartile range; WTR, with-the-rule; ATR, against-the-rule. 
Table 3 Comparisons of variables among different sexes, age groups, and myopic severity groups of the patients with high myopia (N=1,921)

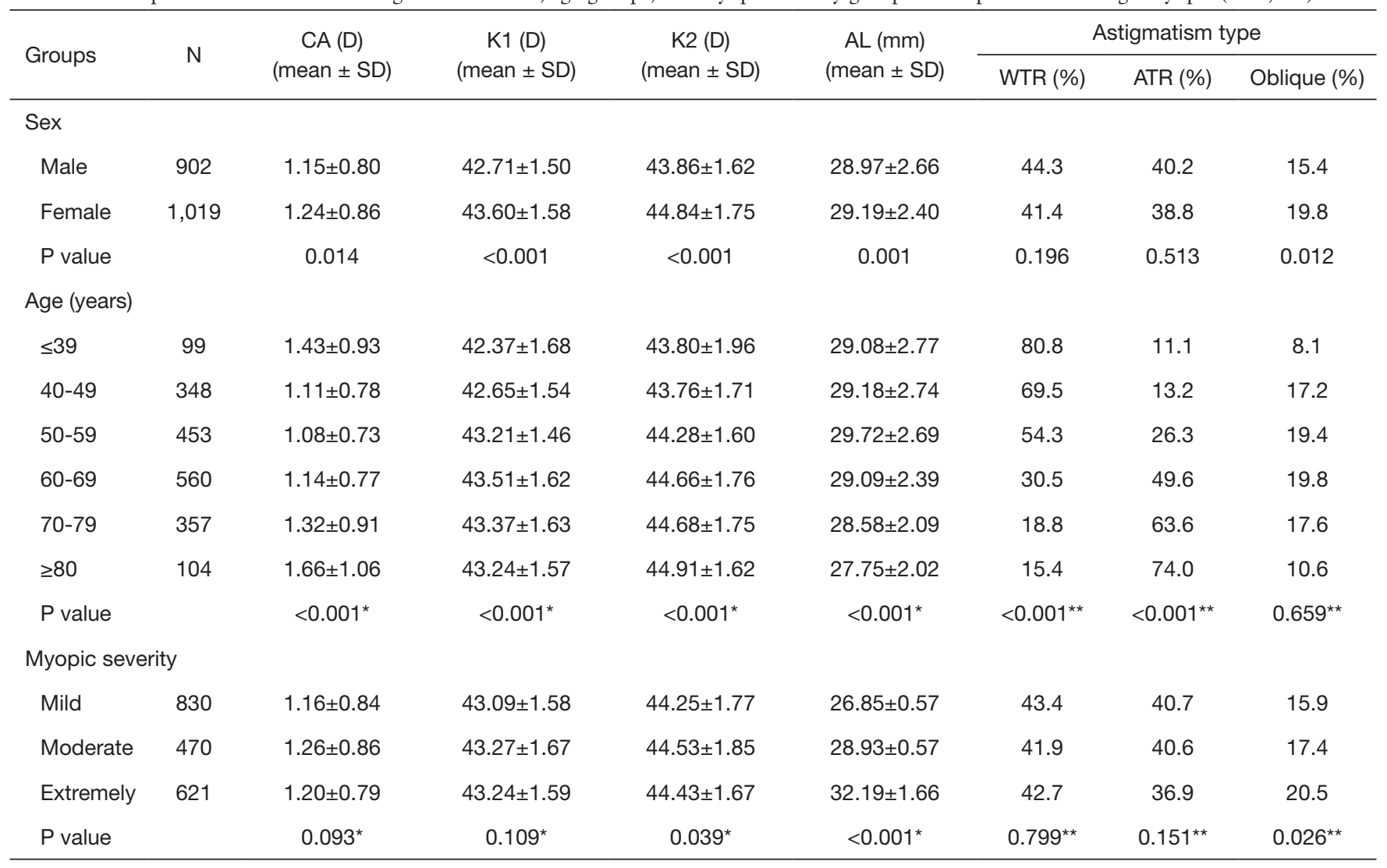

*Trend analysis between different variables and age groups, myopic severity groups was performed using the Jonckheere-Terpstra test. It showed a trend toward increasing mean $\mathrm{CA}$, mean $\mathrm{K} 1$, and mean $\mathrm{K} 2$ with age, a trend toward decreasing mean $\mathrm{AL}$ with age, and a trend toward increasing mean $\mathrm{K} 2$, and mean $\mathrm{AL}$ with myopic severity. ${ }^{* *}$ Trend analysis between the percentages of three astigmatism types and age groups, myopic severity groups was performed by linear regression models. It showed a trend toward decreasing WTR astigmatism with age, a trend toward increasing ATR astigmatism with age, and a trend toward increasing oblique astigmatism with myopic severity. $\mathrm{CA}$, corneal astigmatism; D, dioptres; SD, standard deviation; K1, flat keratometry; K2, steep keratometry; AL, axial length; WTR, with-therule; ATR, against-the-rule.

\section{Discussion}

The distribution of corneal astigmatism in patients with ARCs before cataract surgery has been reported by several studies, and corneal astigmatism $\geq 1.00 \mathrm{D}$ (as a general indication for toric IOL implantation) $(11,28)$ was observed in $37.8-42 \%$ of eyes $(15-17)$. However, the distribution of preoperative corneal astigmatism in cataract surgery candidates with high myopia has remained unclear. In this large, prospective, comparative study, we provided normative data on the distribution of preoperative corneal astigmatism in Chinese cataract surgery candidates with high myopia using a new SS-OCT-based optical biometry tool (IOLMaster 700). In the highly myopic eyes, the mean corneal astigmatism was $1.20 \mathrm{D}, 51.4 \%$ had corneal astigmatism $\geq 1.00 \mathrm{D}$ and $27.4 \%$ had corneal astigmatism $\geq 1.50$ D. Compared with normal AL patients, high myopia patients demonstrated a higher proportion of moderate to high corneal astigmatism $(66.8 \%$ versus $52.6 \%, \mathrm{P}<0.001)$.

In current clinical practice, corneal astigmatism correction during cataract surgery has been identified as an important factor in improving postoperative vision (11). Although limbal relaxing incisions, excimer lasers, femtosecond lasers and other similar procedures could address corneal astigmatism at the time of cataract surgery, toric IOLs are still the preferred approach to correct astigmatism $(11,29)$; they have been shown to be safe and efficacious in highly myopic eyes $(9,30)$, and increasing numbers of surgeons are practising this 
A

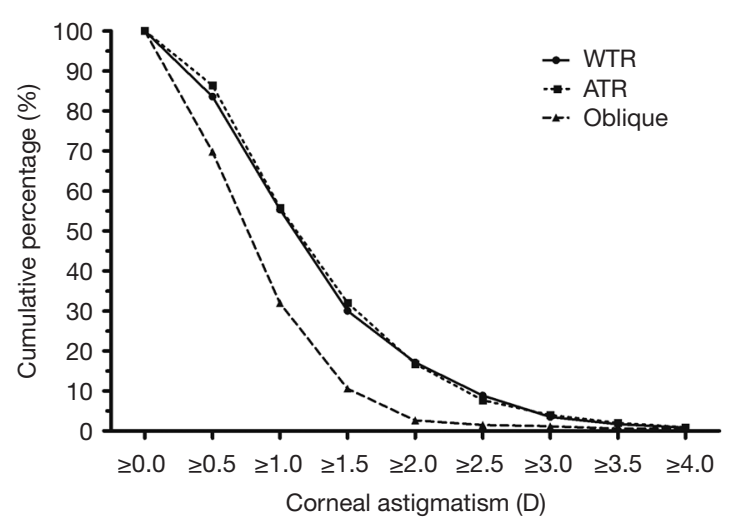

C

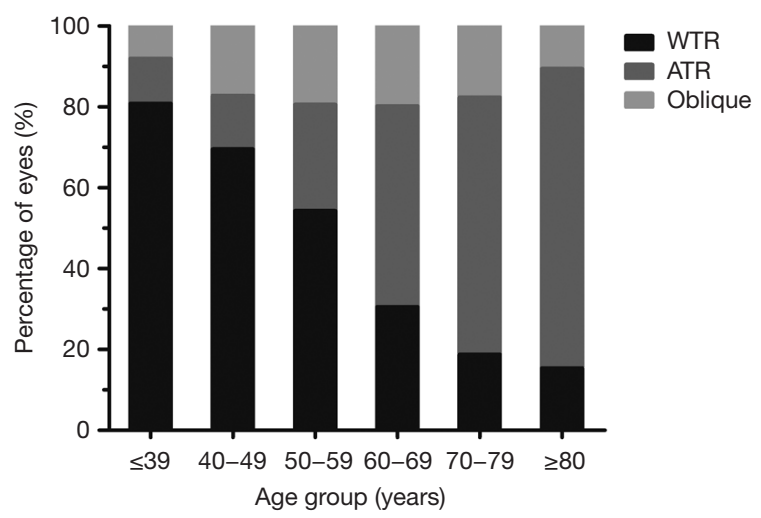

B

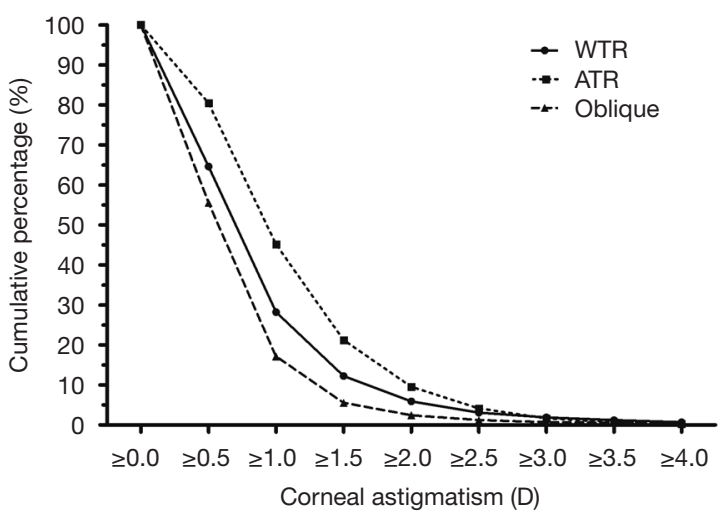

D

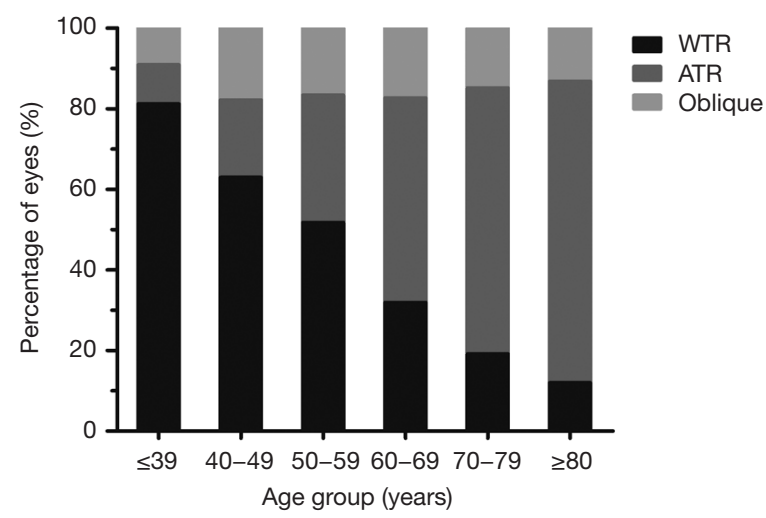

Figure 5 Characteristics of corneal astigmatism in the two groups according to astigmatism type. Line chart showing the distribution of astigmatism cylinder levels across three astigmatism types in the high myopia group (A) and in the control group (B). Stacked histogram showing the percentages of three astigmatism types in the high myopia group (C) and in the control group (D), according to age group. D, dioptres; WTR, with-the-rule; ATR, against-the-rule.

approach. Because patients with high myopia tend to suffer cataracts at a younger age than those without high myopia and have a high incidence of anxiety and depression (>20\%), high myopia patients have higher expectations for postoperative visual function $(1,31,32)$. With the increasing demand for better postoperative visual acuity and spectacle independence, it is crucial to evaluate the distribution of preoperative corneal astigmatism in cataract surgery candidates with high myopia to provide valuable information for the design and manufacture of suitable astigmatism-correcting IOLs and to enable surgeons to select therapeutic strategies.

With the myopia boom that has occurred over the past few decades, the prevalence of myopia in teenagers and young adults has increased to $80-90 \%$ in East and Southeast
Asia, accompanied by a high prevalence of high myopia $(10-20 \%)$ (5). It is widely considered that the increasing prevalence of myopia is driven by environmental and genetic factors, both of which promote progression from mild myopia to high myopia, and the major environmental risk factors that have been identified are less time spent outdoors and higher educational pressures $(7,33)$.

In our study, a high ratio of high myopia (12.8\%), comparable to that reported in young adults (10-20\%) (5), was observed in Chinese cataract surgery candidates. Moreover, almost $1 / 3$ of eyes $(32.3 \%)$ had extreme high myopia, which agrees with clinical observations. The high ratio of high myopia in Chinese cataract surgery candidates may be largely due to genetic susceptibility in this racial group, and may not be due to limited time spent outdoors 
Table 4 Demographic characteristics and corneal astigmatism distributions in the two groups after adjustment for age and sex by propensity score matching

\begin{tabular}{|c|c|c|c|}
\hline Parameter & High myopia group & Control group & $P$ value \\
\hline Patients/eyes (n) & $1,921 / 1,921$ & $1,921 / 1,921$ & \\
\hline \multicolumn{4}{|l|}{ Age (years) } \\
\hline Mean \pm SD & $59.8 \pm 12.6$ & $59.8 \pm 12.6$ & \multirow[t]{2}{*}{0.992} \\
\hline Median (range) & 61 (20 to 95$)$ & 61 (20 to 95$)$ & \\
\hline \multicolumn{4}{|l|}{ Sex, n (\%) } \\
\hline Male & $902(47.0)$ & $895(46.6)$ & \multirow[t]{2}{*}{0.846} \\
\hline Female & $1,019(53.0)$ & $1,026(53.4)$ & \\
\hline \multicolumn{4}{|c|}{ Corneal astigmatism (D) } \\
\hline Mean \pm SD & $1.20 \pm 0.83$ & $0.88 \pm 0.66$ & \multirow[t]{2}{*}{$<0.001$} \\
\hline Median (range) & 1.02 (0 to 7.48$)$ & 0.72 (0 to 5.80$)$ & \\
\hline \multicolumn{4}{|l|}{ K1 (D) } \\
\hline Mean \pm SD & $43.18 \pm 1.61$ & $43.68 \pm 1.43$ & \multirow[t]{2}{*}{$<0.001$} \\
\hline Median (range) & 43.15 (35.08 to 48.82$)$ & 43.66 (39.68 to 48.05$)$ & \\
\hline \multicolumn{4}{|l|}{ K2 (D) } \\
\hline Mean \pm SD & $44.38 \pm 1.76$ & $44.56 \pm 1.50$ & \multirow[t]{2}{*}{0.001} \\
\hline Median (range) & 44.32 (35.43 to 52.78$)$ & 44.51 (40.14 to 52.16$)$ & \\
\hline \multicolumn{4}{|l|}{ Axial length (mm) } \\
\hline Mean \pm SD & $29.09 \pm 2.53$ & $23.54 \pm 0.75$ & \multirow[t]{2}{*}{$<0.001$} \\
\hline Median (range) & $28.48(26.00$ to 37.34$)$ & 23.52 (22.00 to 25.00$)$ & \\
\hline \multicolumn{4}{|c|}{ Astigmatism severity } \\
\hline Low (\%) & 33.2 & 51.8 & $<0.001$ \\
\hline Moderate (\%) & 59.9 & 45.2 & $<0.001$ \\
\hline High (\%) & 6.9 & 3.0 & $<0.001$ \\
\hline \multicolumn{4}{|l|}{ Astigmatism type } \\
\hline WTR (\%) & 42.8 & 42.7 & 1.000 \\
\hline ATR (\%) & 39.5 & 42.5 & 0.057 \\
\hline Oblique (\%) & 17.8 & 14.7 & 0.013 \\
\hline
\end{tabular}

SD, standard deviation; D, dioptres; K1, flat keratometry; K2, steep keratometry; WTR, with-the-rule; ATR, against-the-rule.

or high educational pressures because the older generation in China were not subjected to the same high educational pressures during their childhood as the present generation of young adults $(33,34)$. The mean age of the high myopia patients was 59.8 years, which was much younger than that of the patients with normal ALs $(69.1$ years, $\mathrm{P}<0.001)$ as well as those of ARC patients in China (70.56 years) (15), Thailand (68.21 years) (16), and the UK (79 years) (17); this result is consistent with several other studies that have suggested that patients with high myopia develop cataracts, particularly nuclear cataracts, more rapidly $(3,8,35)$. Moreover, almost half of the high myopia patients $(46.9 \%)$ were relatively younger patients ( $<60$ years of age), and most $(63.1 \%)$ had WTR astigmatism, which can change into ATR astigmatism with increasing age, even after sutureless cataract surgery (36). Based on the current data, we suggest 
that for these relatively younger patients, strategies for correcting preoperative WTR astigmatism should be conservative and should take into consideration the patient's current age and the potential age-related changes that may occur in 5 and 10 years.

The mean corneal astigmatism of the high myopia patients was $1.20 \mathrm{D}$, which was significantly greater than that of the normal AL patients $(0.93 \mathrm{D}, \mathrm{P}<0.001)$, and it was also greater than those reported in patients with ARCs in China (1.01 D) (15), Thailand (1.05 D) (16), and the UK (1.06 D) (17). Moreover, the vast majority of the highly myopic eyes (82.2\%) had at least minimal clinically relevant corneal astigmatism of $0.50 \mathrm{D}$, and a substantial proportion of the eyes had more severe corneal astigmatism of at least $1.00 \mathrm{D}(51.4 \%)$ and $1.50 \mathrm{D}$ (27.4\%); all of these proportions were higher than the respective proportions observed in normal AL eyes $(72.1 \%, 36.0 \%$ and $16.3 \%$, respectively) as well as the proportions reported in eyes with ARCs in the UK ( $78 \%, 42 \%$ and $21 \%$, respectively) (17). In addition, oblique astigmatism, which is more difficult to correct and causes more severe visual symptoms than WTR and ATR astigmatism $(37,38)$, is more common in highly myopic eyes than in normal AL eyes and increases with myopic severity.

Among the patients with high myopia, women had steeper corneas than men, consistent with the findings in the normal AL patients in our study and ARC patients in previous studies $(15,39)$. However, in the high myopia patients, women had greater corneal astigmatism than men, which was inconsistent with the findings in normal AL patients in this study or in ARC patients in a previous study (39) and may be ascribed to the reduced corneal stromal thickness and corneal stiffness in high myopia and negatively associated with myopic severity $(40,41)$. In the high myopia patients, women had longer ALs than men, which may also partly explain this inconsistency. Corneal astigmatism showed a gradually increasing tendency with increasing age after the age of $50(\mathrm{r}=0.134, \mathrm{P}<0.001)$, and ATR astigmatism increased with age in the high myopia patients, which was consistent with the tendencies in normal $\mathrm{AL}$ patients and ARC patients (15).

Because of the significantly different distributions of both age and sex in the patients with high myopia and those with normal ALs, comparisons of corneal astigmatism between the two cohorts were made by PSM. After matching, high myopia patients demonstrated significantly greater corneal astigmatism, a higher proportion of moderate to high corneal astigmatism, and a higher proportion of oblique astigmatism than normal $\mathrm{AL}$ patients, which was consistent with the results before matching in our study. However, after matching, the proportions of WTR astigmatism and ATR astigmatism demonstrated no significant difference ( $\mathrm{P}>0.05$ for both) between the two cohorts, which was consistent with the result that corneal astigmatism shifted with age from WTR to ATR astigmatism in our study and in a previous study on ARCs (15). These findings suggest that ageing plays a key role in the change in astigmatism type in high myopia patients and may be related to the impact of ageing on the cornea and eyelid position $(42,43)$.

The main limitation of the current study was that it was a clinic-based survey and that the patients came from one centre (the Zhongshan Ophthalmic Center) and may not completely represent the prevalence of preoperative corneal astigmatism in the Chinese cataract population with high myopia as a whole; only a community-based epidemiologic survey could provide conclusive evidence.

\section{Conclusions}

The present study analysed the pattern of corneal astigmatism in patients with high myopia before cataract surgery and compared it with that in normal AL patients. A significant burden of preoperative corneal astigmatism was observed in Chinese cataract surgery candidates with high myopia, who exhibited significantly greater astigmatism cylinders and a markedly higher proportion of moderate to high astigmatism than individuals with normal ALs. These results indicated that the majority of high myopia patients need simultaneous correction of astigmatism during cataract surgery, which may help surgeons make appropriate incision and IOL choices and may assist IOL manufacturers in the design of new IOLs for astigmatism correction in the high myopia population.

\section{Acknowledgments}

Funding: This study was supported by grants for the National Key Research and Development Program of China (grant No. 2017YFC1104603), and the National Natural Science Foundation of China (grant No. 81770909, and grant No. 81970783). The funding organization had no role in the design or conduct of this research, or writing of the manuscript.

\section{Footnote}

Reporting Checklist: The authors have completed the 
STROBE reporting checklist Available at http://dx.doi. org/10.21037/atm-20-6757

Data Sharing Statement: Available at http://dx.doi. org/10.21037/atm-20-6757

Peer Review File: Available at http://dx.doi.org/10.21037/ atm-20-6757

Conflicts of Interest: All authors have completed the ICMJE uniform disclosure form (available at http://dx.doi. org/10.21037/atm-20-6757). The authors have no conflicts of interest to declare.

Ethical Statement: The authors are accountable for all aspects of the work in ensuring that questions related to the accuracy or integrity of any part of the work are appropriately investigated and resolved. Ethics approval of the study was obtained from the Human Ethics Committee of the Zhongshan Ophthalmic Center (No. 2019KYPJ124), and informed consent was obtained from all participants. All procedures in the study were performed in adherence with the tenets of the Declaration of Helsinki (as revised in 2013).

Open Access Statement: This is an Open Access article distributed in accordance with the Creative Commons Attribution-NonCommercial-NoDerivs 4.0 International License (CC BY-NC-ND 4.0), which permits the noncommercial replication and distribution of the article with the strict proviso that no changes or edits are made and the original work is properly cited (including links to both the formal publication through the relevant DOI and the license). See: https://creativecommons.org/licenses/by-nc-nd/4.0/.

\section{References}

1. Zhang M, Jing Q, Chen J, et al. Analysis of corneal higherorder aberrations in cataract patients with high myopia. J Cataract Refract Surg 2018;44:1482-90.

2. Zhang J, Tan X, Wang W, et al. Effect of Axial Length Adjustment Methods on Intraocular Lens Power Calculation in Highly Myopic Eyes. Am J Ophthalmol 2020;214:110-8.

3. Praveen MR, Vasavada AR, Jani UD, et al. Prevalence of cataract type in relation to axial length in subjects with high myopia and emmetropia in an Indian population. Am J Ophthalmol 2008;145:176-81.
4. Pan CW, Cheung CY, Aung T, et al. Differential associations of myopia with major age-related eye diseases: the Singapore Indian Eye Study. Ophthalmology 2013;120:284-91.

5. Morgan IG, French AN, Ashby RS, et al. The epidemics of myopia: Aetiology and prevention. Prog Retin Eye Res 2018;62:134-49.

6. Chong EW, Mehta JS. High myopia and cataract surgery. Curr Opin Ophthalmol 2016;27:45-50.

7. Holden BA, Fricke TR, Wilson DA, et al. Global Prevalence of Myopia and High Myopia and Temporal Trends from 2000 through 2050. Ophthalmology 2016;123:1036-42.

8. Liu YC, Wilkins M, Kim T, et al. Cataracts. Lancet 2017;390:600-12.

9. Guo T, Gao P, Fang L, et al. Efficacy of Toric intraocular lens implantation in eyes with high myopia: A prospective, case-controlled observational study. Exp Ther Med 2018;15:5288-94.

10. Ninomiya Y, Minami K, Miyata K, et al. Toric intraocular lenses in eyes with with-the-rule, against-the-rule, and oblique astigmatism: One-year results. J Cataract Refract Surg 2016;42:1431-40.

11. Kessel L, Andresen J, Tendal B, et al. Toric Intraocular Lenses in the Correction of Astigmatism During Cataract Surgery: A Systematic Review and Meta-analysis. Ophthalmology 2016;123:275-86.

12. Behndig A, Montan P, Stenevi U, et al. Aiming for emmetropia after cataract surgery: Swedish National Cataract Register study. J Cataract Refract Surg 2012;38:1181-6.

13. Lehmann RP, Houtman DM. Visual performance in cataract patients with low levels of postoperative astigmatism: full correction versus spherical equivalent correction. Clin Ophthalmol 2012;6:333-8.

14. Tan QQ, Wen BW, Liao X, et al. Optical quality in low astigmatic eyes with or without cylindrical correction. Graefes Arch Clin Exp Ophthalmol 2020;258:451-8.

15. Chen W, Zuo C, Chen C, et al. Prevalence of corneal astigmatism before cataract surgery in Chinese patients. J Cataract Refract Surg 2013;39:188-92.

16. Lekhanont K, Wuthisiri W, Chatchaipun P, et al. Prevalence of corneal astigmatism in cataract surgery candidates in Bangkok, Thailand. J Cataract Refract Surg 2011;37:613-5.

17. Day AC, Dhariwal M, Keith MS, et al. Distribution of preoperative and postoperative astigmatism in a large population of patients undergoing cataract surgery in the 
UK. Br J Ophthalmol 2019;103:993-1000.

18. Jing Q, Tang Y, Qian D, et al. Posterior Corneal Characteristics of Cataract Patients with High Myopia. PLoS One 2016;11:e162012.

19. Heidary G, Ying GS, Maguire MG, et al. The association of astigmatism and spherical refractive error in a high myopia cohort. Optom Vis Sci 2005;82:244-7.

20. Chan SE, Kuo HK, Tsai CL, et al. Astigmatism in Chinese primary school children: prevalence, change, and effect on myopic shift. Jpn J Ophthalmol 2018;62:321-6.

21. Özyol P, Özyol E. Agreement Between Swept-Source Optical Biometry and Scheimpflug-based Topography Measurements of Anterior Segment Parameters. Am J Ophthalmol 2016;169:73-8.

22. Sel S, Stange J, Kaiser D, et al. Repeatability and agreement of Scheimpflug-based and swept-source optical biometry measurements. Cont Lens Anterior Eye 2017;40:318-22.

23. Shajari M, Sonntag R, Ramsauer M, et al. Evaluation of total corneal power measurements with a new optical biometer. J Cataract Refract Surg 2020;46:675-81.

24. Akman A, Asena L, Güngör SG. Evaluation and comparison of the new swept source OCT-based IOLMaster 700 with the IOLMaster 500. Br J Ophthalmol 2016;100:1201-5.

25. Arriola-Villalobos P, Almendral-Gómez J, Garzón N, et al. Agreement and clinical comparison between a new sweptsource optical coherence tomography-based optical biometer and an optical low-coherence reflectometry biometer. Eye (Lond) 2017;31:437-42.

26. Gökce SE, Montes De Oca I, Cooke DL, et al. Accuracy of 8 intraocular lens calculation formulas in relation to anterior chamber depth in patients with normal axial lengths. J Cataract Refract Surg 2018;44:362-8.

27. Jun I, Kang DSY, Reinstein DZ, et al. Clinical Outcomes of SMILE With a Triple Centration Technique and Corneal Wavefront-Guided Transepithelial PRK in High Astigmatism. J Refract Surg 2018;34:156-63.

28. Khan MI, Muhtaseb M. Prevalence of corneal astigmatism in patients having routine cataract surgery at a teaching hospital in the United Kingdom. J Cataract Refract Surg 2011;37:1751-5.

29. Rubenstein JB, Raciti M. Approaches to corneal astigmatism in cataract surgery. Curr Opin Ophthalmol 2013;24:30-4.

30. Mencucci R, Favuzza E, Guerra F, et al. Clinical outcomes and rotational stability of a 4-haptic toric intraocular lens in myopic eyes. J Cataract Refract Surg 2014;40:1479-87.
31. Tan AG, Kifley A, Tham YC, et al. Six-Year Incidence of and Risk Factors for Cataract Surgery in a Multi-ethnic Asian Population: The Singapore Epidemiology of Eye Diseases Study. Ophthalmology 2018;125:1844-53.

32. Yokoi T, Moriyama M, Hayashi K, et al. Predictive factors for comorbid psychiatric disorders and their impact on vision-related quality of life in patients with high myopia. Int Ophthalmol 2014;34:171-83.

33. Saw SM, Matsumura S, Hoang QV. Prevention and Management of Myopia and Myopic Pathology. Invest Ophthalmol Vis Sci 2019;60:488-99.

34. Sensaki S, Sabanayagam C, Verkicharla PK, et al. An Ecologic Study of Trends in the Prevalence of Myopia in Chinese Adults in Singapore Born from the 1920s to 1980s. Ann Acad Med Singap 2017;46:229-36.

35. Pan CW, Cheng CY, Saw SM, et al. Myopia and agerelated cataract: a systematic review and meta-analysis. Am J Ophthalmol 2013;156:1021-33.e1.

36. Hayashi K, Hirata A, Manabe S, et al. Long-term change in corneal astigmatism after sutureless cataract surgery. Am J Ophthalmol 2011;151:858-65.

37. Zuo C, Gong R, Chen W, et al. Investigation of Corneal Astigmatism in Chinese Patients With Primary Angle Closure Disease. J Glaucoma 2018;27:1131-5.

38. Vinas M, de Gracia P, Dorronsoro C, et al. Astigmatism impact on visual performance: meridional and adaptational effects. Optom Vis Sci 2013;90:1430-42.

39. Cui Y, Meng Q, Guo H, et al. Biometry and corneal astigmatism in cataract surgery candidates from Southern China. J Cataract Refract Surg 2014;40:1661-9.

40. Kim BJ, Ryu IH, Lee JH, et al. Correlation of Sex and Myopia With Corneal Epithelial and Stromal Thicknesses. Cornea 2016;35:1078-83.

41. Long $\mathrm{W}, \mathrm{Zhao} \mathrm{Y}, \mathrm{Hu} \mathrm{Y}$, et al. Characteristics of Corneal Biomechanics in Chinese Preschool Children With Different Refractive Status. Cornea 2019;38:1395-9.

42. Goto T, Klyce SD, Zheng X, et al. Gender- and agerelated differences in corneal topography. Cornea 2001;20:270-6.

43. Lieberman DM, Grierson JW. The lids influence on corneal shape. Cornea 2000;19:336-42.

Cite this article as: Tan Y, Liu L, Li J, Qin Y, Sun A, Wu M. Evaluation of preoperative corneal astigmatism using sweptsource optical biometry in Chinese cataract surgery candidates with high myopia: a prospective, comparative observational study. Ann Transl Med 2021;9(8):618. doi: 10.21037/atm-20-6757 